\title{
Effects of treatment with an Hsp90 inhibitor in tumors based on 15 phase II clinical trials
}

\author{
HE WANG ${ }^{1 *}$, MINGJIE LU²*, MENGQIAN YAO ${ }^{2}$ and WEI ZHU ${ }^{2}$ \\ ${ }^{1}$ Department of Oncology, The Third Affiliated Hospital of Nanjing Medical University, Nanjing 211100; \\ ${ }^{2}$ Department of Oncology, The First Affiliated Hospital of Nanjing Medical University, Nanjing 210029, P.R. China
}

Received February 15, 2016; Accepted July 1, 2016

DOI: $10.3892 / \mathrm{mco} .2016 .963$

\begin{abstract}
Heat shock protein (Hsp)90 serves as a chaperone protein that promotes the proper folding of proteins involved in a variety of signal transduction processes involved in cell growth. Hsp90 inhibitors, which inhibit the activity of critical client proteins, have emerged as the accessory therapeutic agents for multiple human cancer types. To better understand the effects of Hsp90 inhibitors in cancer treatment, the present study reviewed 15 published phase II clinical trials to investigate whether Hsp90 inhibitors will benefit patients with cancer. Information of complete response, partial response, stable disease, objective response and objective response rate was collected to evaluate clinical outcomes. Overall, Hsp90 inhibitors are effective against a variety of oncogene-addicted cancers, including those that have developed resistance to specific receptors.
\end{abstract}

\section{Introduction}

Tumors are one of the most common lethal diseases worldwide, with 14 million new cases diagnosed annually. They are also the leading cause of mortality worldwide, causing 8.2 million mortalities annually, as reported in the World Health Organization World Cancer Report 2014. Although cytotoxic chemotherapy has revolutionized the prognosis for patients with most tumor types, survival remains dismal as a whole and exploring the novel therapeutic approaches is required. Considering that oncoproteins serve a pivotal role in tumorigenesis, molecular target therapies in different types of tumor have been more and more crucial and promising.

The molecular chaperone, heat shock protein (Hsp)90, serves an important role in the formation, stability and function

Correspondence to: Dr Wei Zhu, Department of Oncology, The First Affiliated Hospital of Nanjing Medical University, 300 Guangzhou Road, Nanjing 210029, P.R. China

E-mail: zhuwei@njmu.edu.cn

*Contributed equally

Key words: Hsp90 inhibitor, clinical trial, genotype, tumor of the proteins involved in cell growth and survival signaling pathways (1). The ability of Hsp90 to chaperone protein kinases or transcription factors is dependent on the binding and hydrolysis of ATP at its binding domain (2). Accordingly, multiple mitogenic pathways may be inhibited by synthetic inhibitors of the Hsp90 ATPase activity, including 17-allylamino-17-demthoxygeldanamycin (17-AAG), ganetespib, retaspimycin $\mathrm{HCl}$ (IPI-504) and BIIB021 (3-7). Evidence of the activity of Hsp90 inhibitors was shown in vitro, and animal models of different types of tumor and numerous clinical trials were performed to search for novel treatments against tumors (8-12). The present study summarized 15 phase II clinical trials using Hsp90 inhibitors and found that the lack of efficacy of Hsp90 inhibitors in these initial phase II studies may be due to the treatment-associated toxicity limitation, accounting for insufficient dose of drug or infrequent schedule of administration, which in turn leads to inadequate inhibition of target proteins. Additionally, the clinical activity of Hsp90 inhibitors suggested a potential cancer therapy against a variety of oncogene-addicted cancer types, including those that have developed resistance to specific receptors.

\section{Methods and materials}

Identification of eligible studies. PubMed (http://www.ncbi. nlm.nih.gov/pubmed) was searched using the search terms (last search updated 10 ${ }^{\text {th }}$ December 2015) 'Hsp90 inhibitor' and 'cancer' with no limitations. In addition, another search strategy was also performed using the terms 'Hsp90 inhibitor' (limited to humans), 'clinical trial' and 'cancer'. Information found on the ClinicalTrials.gov website (www.clinicaltrials. gov), a registry and results database of publicly and privately supported clinical studies using human participants performed worldwide, was also reviewed. All relevant publications were reviewed and duplications of articles from the two search strategies were eliminated. The articles in reference lists were also hand-searched for potentially relevant publications. The search was performed by two investigators. Any disagreements were resolved by consensus with the involvement of a third author.

Inclusion criteria. All human-associated studies, regardless of tumor types, were included once they met the following criteria: Malignant tumor, monotherapy with Hsp90 inhibitor or Hsp90 inhibitor combined with other antitumor drugs, 
histological confirmation, relatively stable administration dosage of Hsp90 inhibitor and sufficient data of clinical outcomes.

Data extraction. Two investigators extracted data independently and reached a consensus on all items. For each study, the following information was collected: First author, year of publication, country of the first author, the number of total and evaluable patients, median age, gender, cancer type, stage, prior treatment, name of Hsp90 inhibitor or other combined drugs, dose regimen, median cycle of treatment, clinical outcomes, including the number of patients who achieved stable disease (SD), partial response (PR), complete response (CR), objective response (OR) or progressive disease (PD). Other evaluation data, including the median overall survival (OS), progression-free survival (PFS), time to progression (TTP) and response of duration (DR) were also collected. For studies including different tumor types, data were extracted separately by tumor types if there was enough information in the text. Additionally, the studies mentioning genomic alteration were extracted separately to investigate if Hsp90 inhibitors have the ability to overcome resistance to receptor-specific targeted treatments.

\section{Results}

Literature search. A total of 1,261 published articles were identified from PubMed and 1,110 duplicated and unrelated articles were excluded. Within the remaining 50 publications related to clinical trials, articles were excluded if administration dosage of Hsp90 inhibitor was not stable; all Phase I studies were excluded for this reason. Therefore, a total of 15 articles were eligible for assessment in the present study. Of these 15 articles, 9 mentioned that genomic alteration were extracted separately, as discussed later.

Due to the heterogeneity of patients, Hsp90 inhibitor types, regimens, clinical settings and a large variety of outcome measurement used in these trials and pooling of data for meta-analysis was inappropriate. The results were, therefore, summarized qualitatively.

Study characteristics. Details from 15 eligible trials published between 2006 and 2014 were analyzed in Table I. All first authors were based in the USA. The number of patients in these trials ranged between 11 and 99, with the median age between 51 and 68 years. A total of 10 types of cancer were described in these 15 trials, including breast cancer (13-16), ovarian carcinoma (17), peritoneal carcinoma (17), multiple myeloma (18), renal cell cancer (19), prostate cancer $(20,21)$, melanoma $(22,23)$, colorectal cancer $(24)$, lung cancer $(25,26)$ and gastrointestinal stromal tumor (GIST) (27). The majority of patients had received prior therapies and had metastatic or recurrent diseases at baseline.

Treatment administration. Details of eligible trials with an Hsp90 inhibitor were noted in Table II. The majority of Hsp90 inhibitors were tested in trials of monotherapy: 17-A AG $(13,19,20,23)$, ganetespib $(15,24,25)$, IPI-504(21,26) andBIIB021 (27). There were alsotrials of combination of Hsp90 inhibitors, 17-AAG $(14,17,18) /$ IPI-504 (16), with other anticancer drugs, including cytotoxic and molecularly targeted agents.
The majority of Hsp90 inhibitors were administered by intravenous infusion. For 17-AAG, the dosage was $50 / 175 / 220 / 340 \mathrm{mg} / \mathrm{m}^{2}$ on days $1,4,8$ and 11 of a 21-day cycle; or $300 / 450 \mathrm{mg} / \mathrm{m}^{2}$ on days 1,8 and 15 of a 28-day cycle; $154 \mathrm{mg} / \mathrm{m}^{2}$ on days $1,8(1,9)$ of a 21 -day cycle; $450 \mathrm{mg} / \mathrm{m}^{2}$ weekly. For ganetespib, the dosage was $200 \mathrm{mg} / \mathrm{m}^{2}$ on days 1,8 and 15 of a 28 -day cycle. For IPI-504, the dosage was $400 \mathrm{mg} / \mathrm{m}^{2}$ on days 1,48 and 11 of a 21-day cycle or $300 \mathrm{mg} / \mathrm{m}^{2}$ weekly. Treatment with BIIB021 was administered as a $600 \mathrm{mg}$ dose twice a week or $400 \mathrm{mg}$ three times a week. The median cycle of each treatment was summarized in Table II.

In trials combining an Hsp90 inhibitor with other drugs, three added the molecularly targeted agent trastuzumab/bortezomib to 17-AGG or IPI-504, and one added the cytotoxic drug gemcitabine to $17-\mathrm{AGG}(14,16-18)$. The median cycle of each treatment was summarized in Table II.

Clinical outcomes. Response criteria were used, as defined by the Response Evaluation Criteria in Solid Tumors (12-15, 17,20,22-26), the European Group for Bone and Marrow Transplantation criteria (18), the Prostate-Specific Antigen Working Group (19), the NCI Prostate-Specific Antigen Working Group (21) and the EORTC guidelines (27). Overall, Hsp90 inhibitors are effective against a variety of oncogene-addicted cancer types, including those that have developed resistance to specific receptors.

Of the 15 trials that used Hsp90 inhibitors, OR was observed in 7 studies, with ORR ranging between 0.04 and 0.22 , demonstrating that in tumors driven by client proteins are hypersensitive to Hsp90 inhibition at the currently deliverable doses and schedules (14,15,17,18,25-27). Modi et al (14) demonstrated that 17-AAG is effective in advanced trastuzumab-refractory human epidermal growth factor receptor (HER)2-positive breast cancer. In that previous study, the OR was $22 \%$, the clinical benefit rate $(\mathrm{CR}+\mathrm{PR}+\mathrm{SD})$ was $59 \%$, the median PFS was 6 months and the median OS was 17 months. Consistent results were observed in metastatic breast cancer $(\mathrm{MBC})$ that used ganetespib as a single agent, the clinical benefit rate (CR + PR + SD >6 months) was 9\%, median PFS was 7 weeks and median OS was 46 weeks (15). Socinski et al (25) found that ganetespib showed encouraging single-agent activity in heavily pretreated chemotherapy patients with advanced non-small cell lung cancer (NSCLC) that harbored anaplastic lymphoma kinase (ALK) rearrangement. Sequist et al (26) observed the identical phenomenon in the trial using IPI-504. Among the three patients with NSCLC harboring the ALK rearrangement, which progressed following epidermal growth factor receptor (EGFR) tyrosine kinase inhibitor (TKI) therapy, two had PR and the third had prolonged SD. OR was also observed in trials that used 17-AAG combined with gemcitabine (17) or bortezomib (18). This was also observed in trials combining IPI-504 with these drugs (27). The authors hypothesized that an Hsp90 inhibitor performed the action efficiently by degrading the client proteins, including Chk1, proteasome, c-Kit and platelet-derived growth factor receptor $\alpha$. The results mentioned above were relative to oncogenes, and therefore, the present study extracted trials using the Hsp90 inhibitor in tumors harboring genotype alteration to explore whether the Hsp90 inhibitor has the ability to overcome 


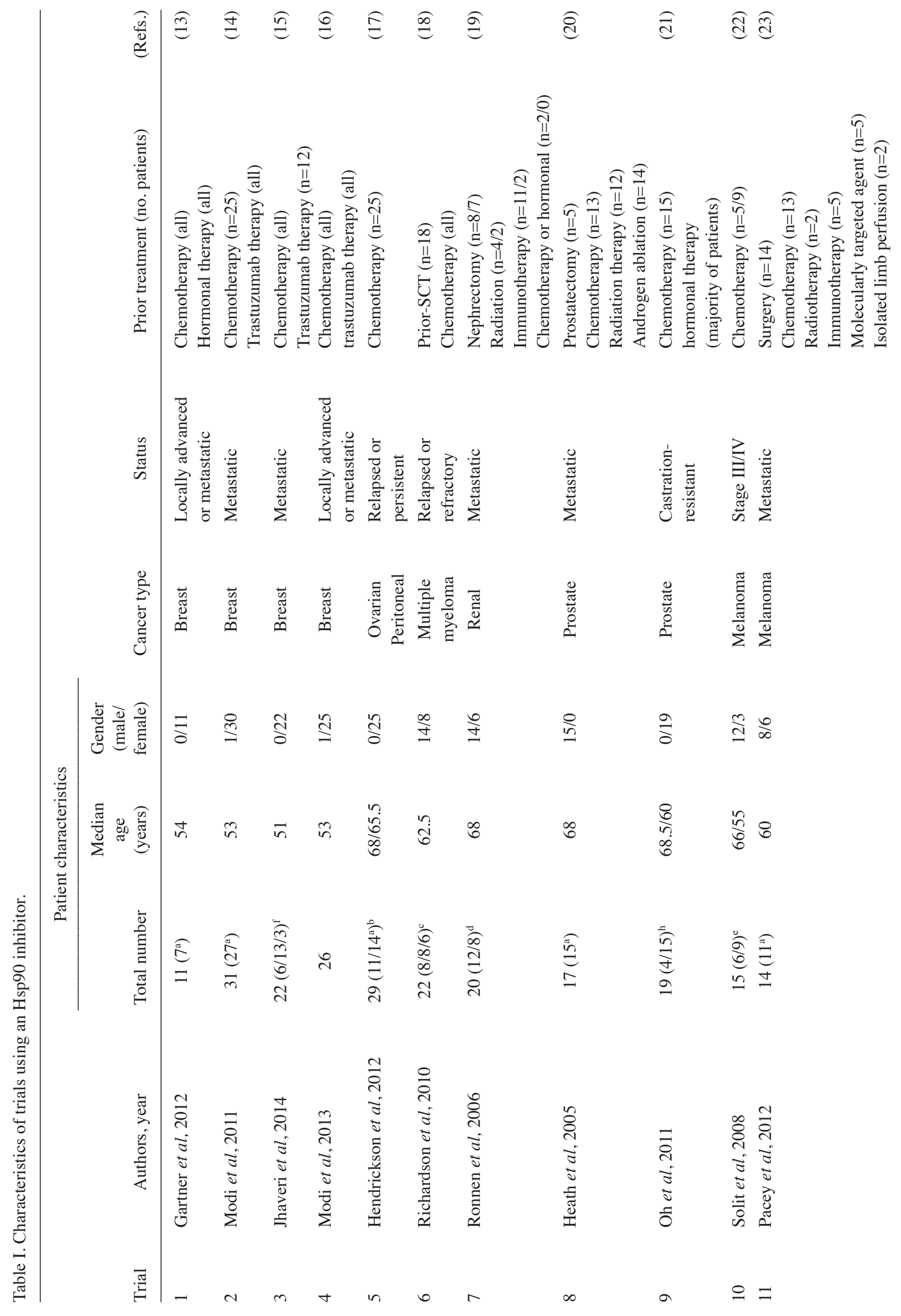




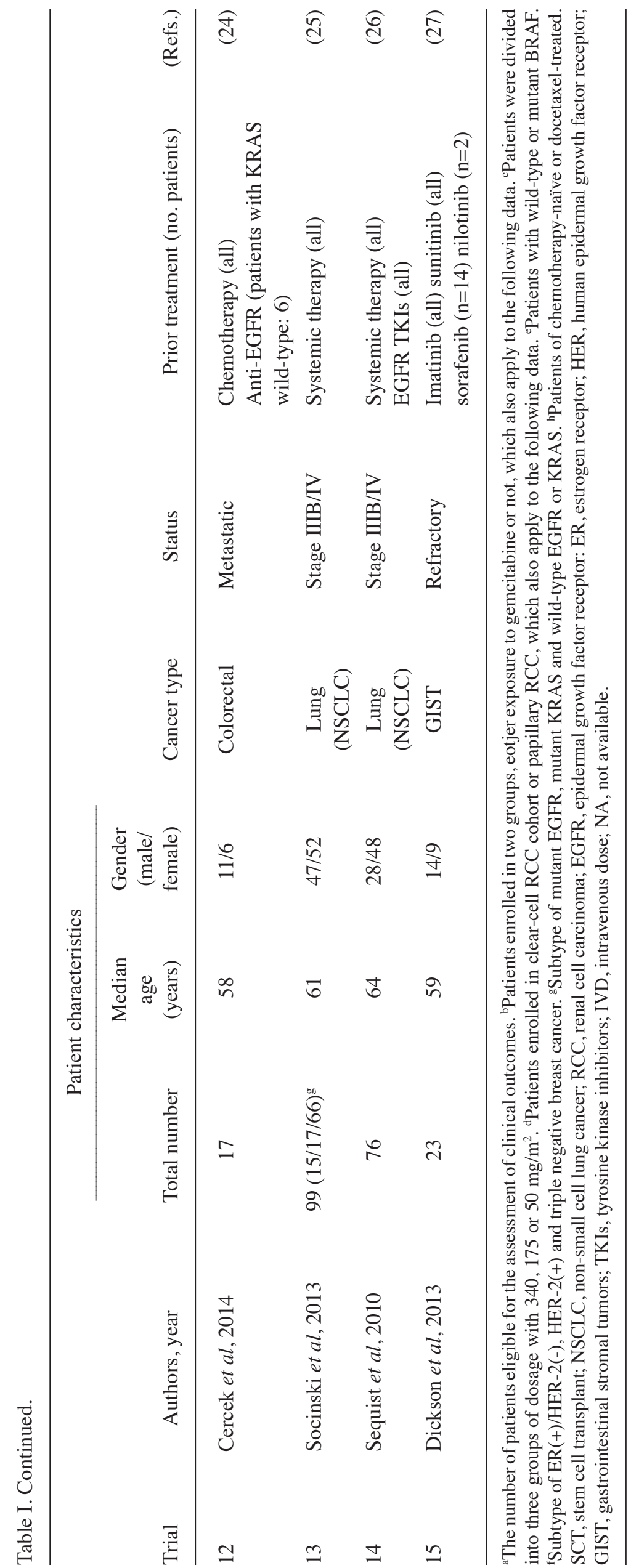




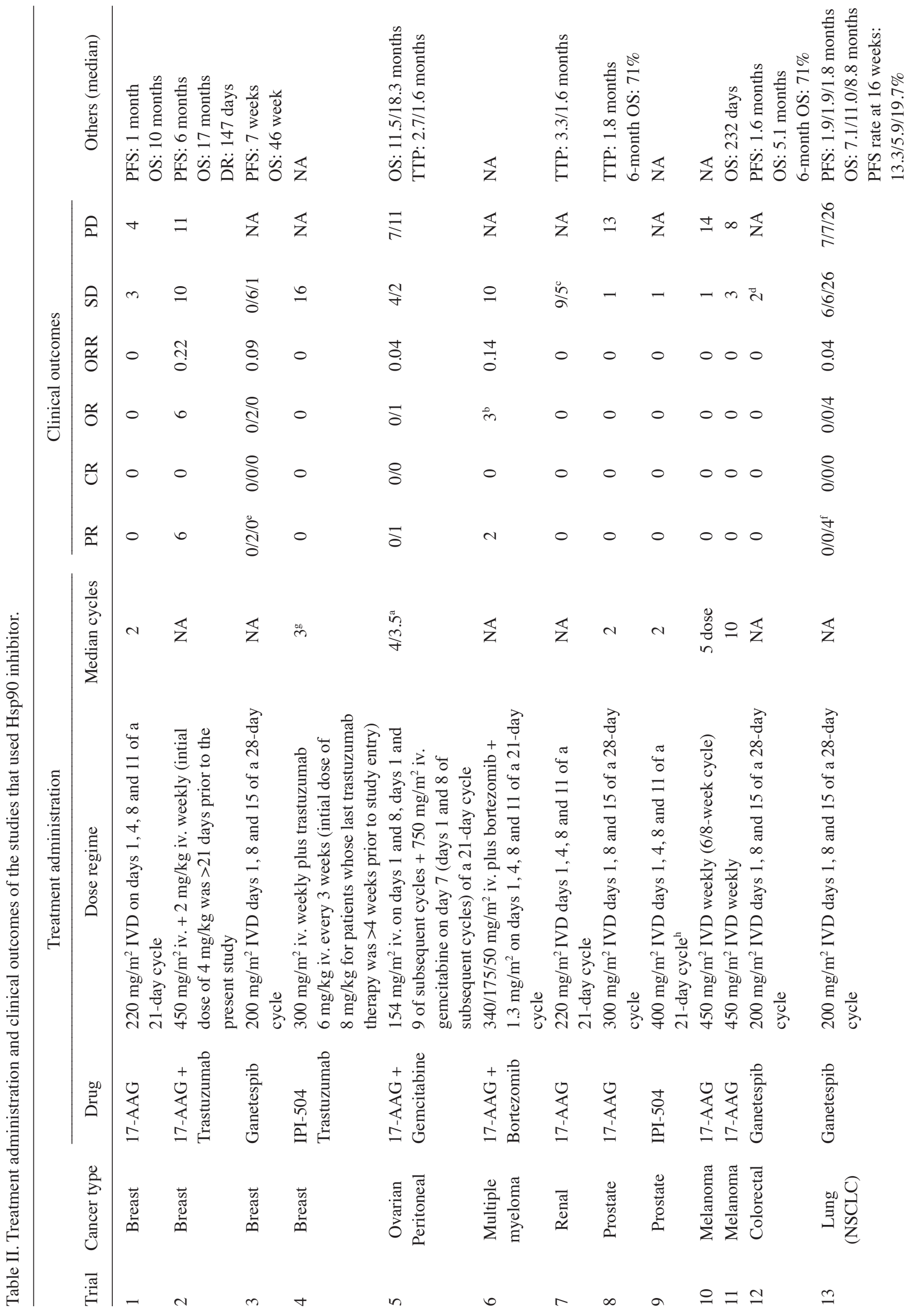




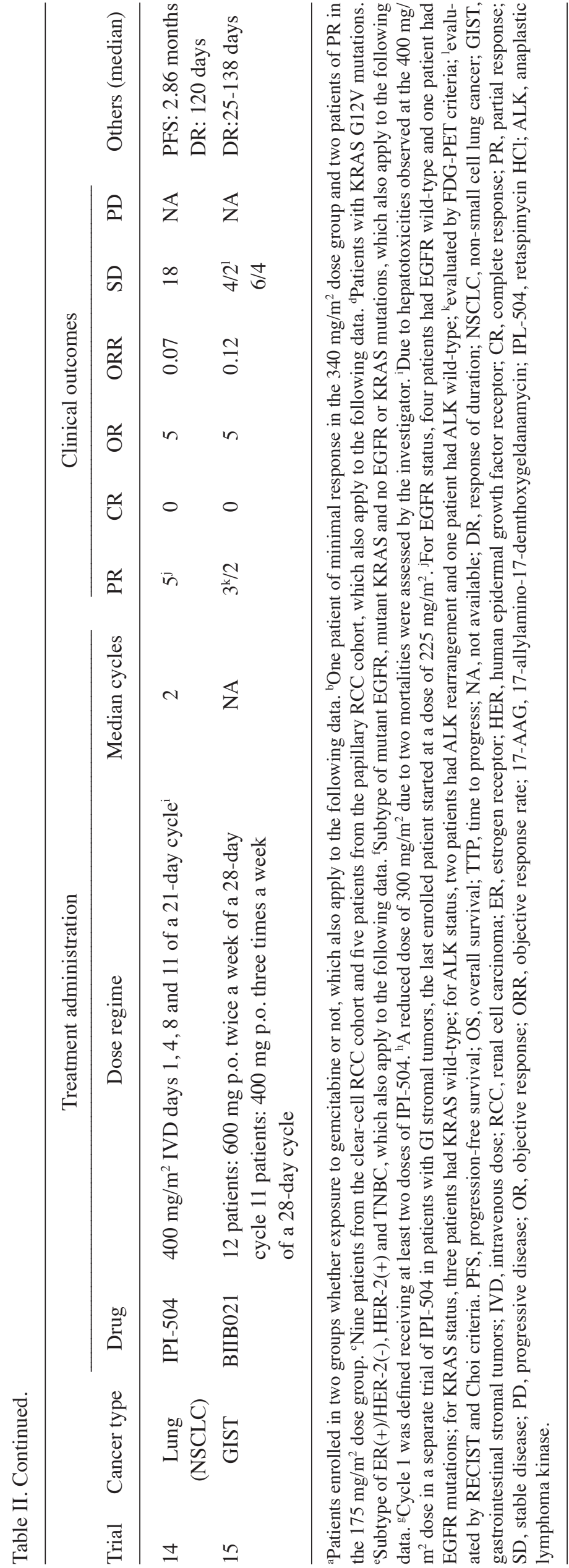




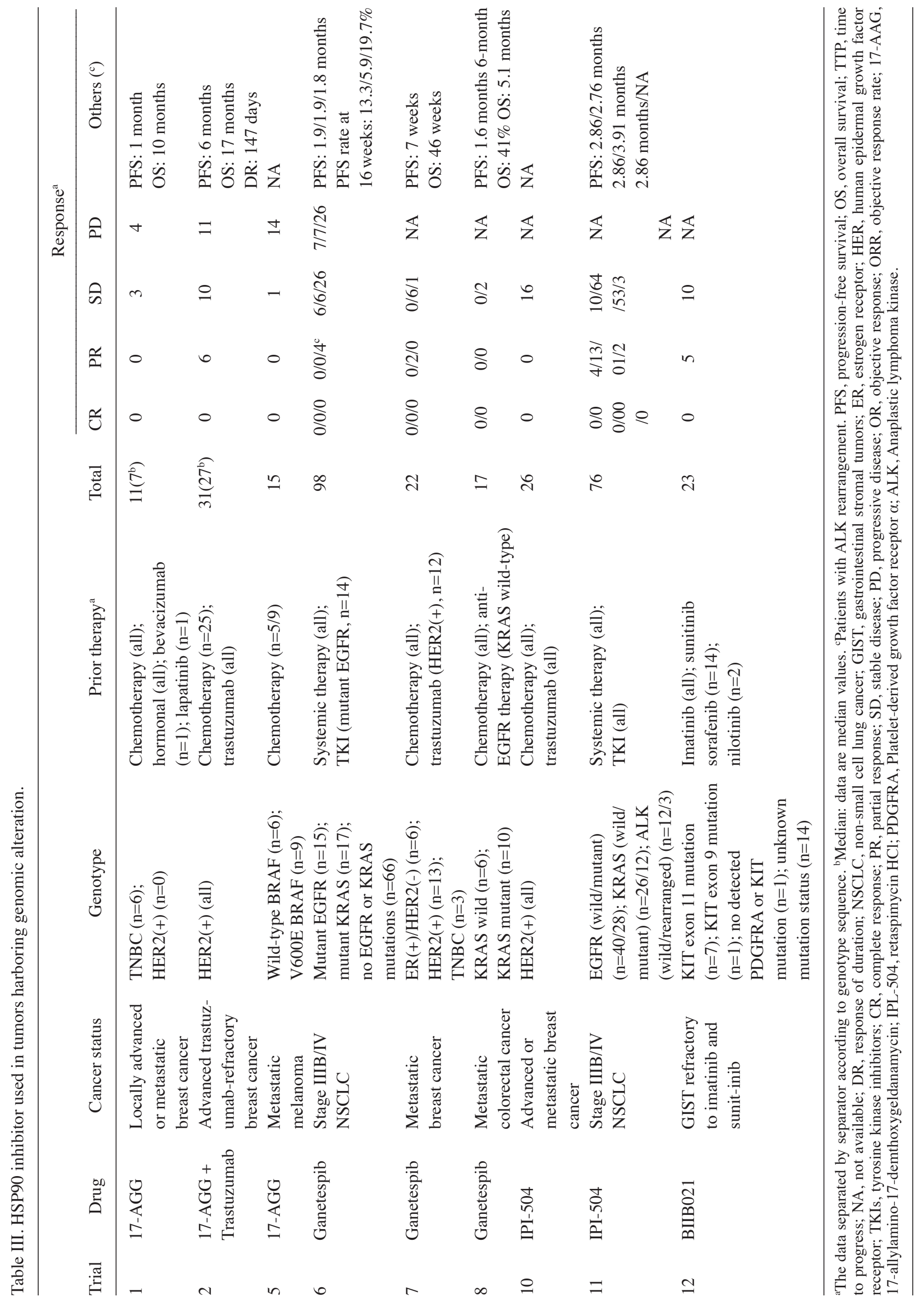


resistance to receptor-specific targeted treatments. The results are shown in Table III.

Additionally, trials that failed to achieve OR are also summarized in Table II. The lack of efficacy of Hsp90 inhibitors in these initial phase II studies may be due to treatment-associated toxicity limitations, accounting for insufficient dose of drug or infrequent schedule of administration, which leads to the lack of adequate inhibition of target proteins.

\section{Discussion}

Hsp90 is a chaperone for a wide variety of signaling proteins, many of which serve an important role in tumorigenesis, including HER2, EGFR, Akt, c-RAF, BRAF and re-arranged ALK (28-33). Loss of Hsp90 function leads to ubiquitination and degradation of these proteins, causing cell growth inhibition, apoptosis of tumor cells and antitumor activity in preclinical models (8-12). These preclinical observations have prompted the clinical assessment of Hsp90 inhibitors in various tumor types.

The present review summarized 15 phase II clinical trials of different types of tumor and found that the Hsp90 inhibitor may be a potential agent against tumors via the inhibition of intended client proteins. Modi et al (14) and Socinski et al (15) have proved the antitumor activity of 17-AAG and ganetespib, respectively, for patients with HER2-positive MBC which progressed following trastuzumab administration. Notably, p95HER2 is an Hsp90 target that is degraded by Hsp90 inhibitors (28). Furthermore, trastuzumab-resistant models with overexpression of p95HER2 are sensitive to Hsp90 inhibitors. Sustained loss of HER2 and p95HER2 expression, and inhibition of AKT activation with regulatory administration of Hsp90 inhibitors resulted in apoptosis of cancer cells and inhibition of tumor growth. Data from previous studies of NSCLC show that lower concentrations of Hsp90 inhibitors may be required to inhibit the expression of echinoderm microtubule associated protein like 4-ALK compared with mutant EGFR, all of which had previously received and acquired resistance to lines of chemotherapy or EGFR TKIs, respectively $(25,26)$. Additionally, induction of small cell histological changes or epithelial-mesenchymal transition may have been present in certain cases and may have contributed to the lack of durable clinical activity for patients with EGFR mutations with Hsp90 inhibitors (29).

Tillotson et al (30) revealed that Hsp70 may be a biomarker for predicting the antitumor activity of Hsp90 inhibitors (30). Furthermore, the authors demonstrated that response to Hsp90 inhibitors is correlated to the extent of downregulation of client proteins, which relies on occupancy of Hsp90 (30-33). Inhibition of Hsp90 may induce bortezomib-triggered apoptosis, even in drug-resistant multiple myeloma cells, due to upregulation of plasma Hsp70 and downregulation of proteasomal activity (18). Although partial downregulation of Chk1 was observed after 17-AAG administration, the 17-AAG/gemcitabine combination showed limited anticancer activity in patients with advanced epithelial ovarian and primary peritoneal carcinoma, probably attributed to insufficient downregulation of client proteins, including HER2, insulin-like growth factor 1 receptor, insulin receptor, Akt and c-Raf, at currently used doses (17). Accumulating evidence has suggested that the interaction of client proteins with the
Hsp90 chaperone is a multifaceted process, with certain kinases forming stable heterocomplexes with the chaperone machinery and others forming more dynamic complexes that are more readily disassembled, and in which the client is more modestly ubiquitinated (34). These differences may contribute to the hierarchy of sensitivity of clients to degradation.

The lack of efficacy of Hsp90 inhibitors in these initial phase II studies may be due to the treatment-associated toxicity limitation accounting for insufficient dose of drug or infrequent schedule of administration, which leads to the lack of adequate inhibition of target proteins. Although overexpression of Hsp72 and low expression of Hsp90 were detected, the client proteins, including HER 2 and cyclin-dependent kinase (CDK)4 depletion were not consistently detected in patients with metastatic melanoma (23). The lack of objective tumor responses is consistent with what has been reported in hormone-refractory prostate cancer (20) and in renal cell carcinoma (19) using lower doses of 17-AAG. No significant changes in interleukin (IL)-6, IL-8 and maspin in metastatic, hormone-refractory prostate cancer with 17-AAG may lead to failure of prostate-specific antigen response (20). Preclinical studies have demonstrated that both suppression of client proteins within 24-72 $\mathrm{h}$ and sufficient administration of Hsp90 inhibitors are required to induce antitumor effects (35). At the time of the posttreatment biopsy (median, $44 \mathrm{~h}$ after dose 1), an increase in Hsp70 levels and a decrease in cyclin D1 levels were detected (22). These findings, together with the observation of changes in RAF-1 and CDK 4 at $24 \mathrm{~h}$ in another study (32), suggested that transient decreases in raf kinases, phosphorylated-extracellular signal-regulated kinase-1 and CDK4 may have occurred. However, these changes in the components of the mitogen-activated protein kinase pathway were not sufficient to cause tumor shrinkage. Clinically, frequent dosing schedules have been restricted by the toxicity observed in patients. The death of two patients with castration-resistant prostate cancer, treated with IPI-504 at a dose of $400 \mathrm{mg} / \mathrm{m}^{2}$ on days 1, 4, 8 and 11 of a 21-day cycle, was a result of drug-related events of hepatic failure and ketoacidosis, respectively (21).

In conclusion, only tumor types driven by client proteins that are hypersensitive to Hsp90 inhibition will be susceptible to the effects of Hsp90 inhibitors at the currently doses and schedules. The present review summarized 15 phase II clinical trials using Hsp90 inhibitors and found that Hsp90 inhibitors may be a potential cancer therapy against a variety of oncogene-addicted cancer types, including those developing resistance to specific receptors.

\section{Acknowledgements}

The present study was funded by the continuous financial support from the National Natural Science Foundation of China Youth Found (no. 81501980).

\section{References}

1. Taipale M, Jarosz DF and Lindquist S: HSP90 at the hub of protein homeostasis: Emerging mechanistic insights. Nat Rev Mol Cell Biol 11: 515-528, 2010.

2. Meissner A, Petersenn S, Heidemann HT, Osterkamp U, Simon R and Schulte HM: Pharmacokinetics of oral isosorbide-5-mononitrate in patients with ischemic heart failure. Klin Wochenschr 69: 213-219, 1991. 
3. Ramanathan RK, Trump DL, Eiseman JL, Belani CP, Agarwala SS, Zuhowski EG, Lan J,Potter DM, Ivy SP, Ramalingam S, et al: Phase I pharmacokinetic-pharmacodynamic study of 17-(allylamino)-17-demethoxygeldanamycin (17AAG, NSC 330507), a novel inhibitor of heat shock protein 90 , in patients with refractory advanced cancers. Clin Cancer Res 11: 3385-3391, 2005.

4. Grem JL, Morrison G, Guo XD, Agnew E, Takimoto CH, Thomas R, Szabo E, Grochow L, Grollman F, Hamilton JM, et al: Phase I and pharmacologic study of 17-(allylamino)-17-demethoxygeldanamycin in adult patients with solid tumors. J Clin Oncol 23: 1885-1893, 2005.

5. Goldman JW, Raju RN, Gordon GA, El-Hariry I, Teofilivici F, Vukovic VM, Bradley R, Karol MD, Chen Y, Guo W, et al: A first in human, safety, pharmacokinetics, and clinical activity phase I study of once weekly administration of the Hsp90 inhibitor ganetespib (STA-9090) in patients with solid malignancies. BMC Cancer 13: 152, 2013

6. Saif MW, Takimoto C, Mita M, Banerji U, Lamanna N, Castro J, O'Brien S, Stogard C and Von Hoff D: A phase 1, dose-escalation, pharmacokinetic and pharmacodynamic study of BIIB021 administered orally in patients with advanced solid tumors. Clin Cancer Res 20: 445-455, 2014.

7. Wagner AJ, Chugh R, Rosen LS, Morgan JA, George S, Gordon M, Dunbar J, Normant E, Grayzel D and Demetri GD: A phase 1 study of the HSP90 inhibitor retaspimycin hydrochloride (IPI-504) in patients with gastrointestinal stromal tumors or soft-tissue sarcomas. Clin Cancer Res 19: 6020-6029, 2013.

8. Uozaki H, Ishida T, Kakiuchi C, Horiuchi H, Gotoh T, Iijima T, Imamura T and Machinami R: Expression of heat shock proteins in osteosarcoma and its relationship to prognosis. Pathol Res Pract 196: 665-673, 2000

9. Chiosis G and Neckers L: Tumor selectivity of Hsp90 inhibitors: The explanation remains elusive. ACS Chem Biol 1: 279-284, 2006.

10. Moulick K, Ahn JH, Zong H, Rodina A, Cerchietti L, Gomes DaGama EM, Caldas-Lopes E, Beebe K, Perna F, Hatzi K, et al: Affinity-based proteomics reveal cancer-specific networks coordinated by Hsp90. Nat Chem Biol 7: 818-826, 2011

11. Garcia-Carbonero R, Carnero A and Paz-Ares L: Inhibition of HSP90 molecular chaperones: Moving into the clinic. Lancet Oncol 14: e358-e369, 2013.

12. Taldone T, Patel HJ, Bolaender A, Patel MR and Chiosis G: Protein chaperones: A composition of matter review (2008-2013). Expert Opin Ther Pat 24: 501-518, 2014.

13. Gartner EM, Silverman P, Simon M, Flaherty L, Abrams J, Ivy P and Lorusso PM: A phase II study of 17-allylamino-17-demethoxygeldanamycin in metastatic or locally advanced, unresectable breast cancer. Breast Cancer Res Treat 131: 933-937, 2012.

14. Modi S, Stopeck A, Linden H, Solit D, Chandarlapaty S, Rosen N, D'Andrea G, Dickler M, Moynahan ME, Sugarman S, et al: HSP90 inhibition is effective in breast cancer: A phase II trial of tanespimycin (17-AAG) plus trastuzumab in patients with HER2-positive metastatic breast cancer progressing on trastuzumab. Clin Cancer Res 17: 5132-5139, 2011.

15. Jhaveri K, Chandarlapaty S, Lake D, Gilewski T, Robson M, Goldfarb S, Drullinsky P, Sugarman S, Wasserheit-Leiblich C, Fasano J, et al: A phase II open-label study of ganetespib, a novel heat shock protein 90 inhibitor for patients with metastatic breast cancer. Clin Breast Cancer 14: 154-160, 2014.

16. Modi S, Saura C, Henderson C, Lin NU, Mahtani R, Goddard J, Rodenas E,Hudis C, O'Shaughnessy J and Baselga J: A multicenter trial evaluating retaspimycin HCL (IPI-504) plus trastuzumab in patients with advanced or metastatic HER2-positive breast cancer. Breast Cancer Res Treat 139: 107-113, 2013.

17. Hendrickson AE, Oberg AL, Glaser G, Camoriano JK, Peethambaram PP, Colon-Otero G, Erlichman C, Ivy SP, Kaufmann SH, Karnitz LM and Haluska P: A phase II study of gemcitabine in combination with tanespimycin in advanced epithelial ovarian and primary peritoneal carcinoma. Gynecol Oncol 124: 210-215, 2012.

18. Richardson PG, Badros AZ, Jagannath S, Tarantolo S, Wolf JL, Albitar M, Berman D, Messina M and Anderson KC: Tanespimycin with bortezomib: Activity in relapsed/refractory patients with multiple myeloma. Br J Haematol 150: 428-437, 2010.

19. Ronnen EA, Kondagunta GV, Ishill N, Sweeney SM, Deluca JK Schwartz L, Bacik J and Motzer RJ: A phase II trial of 17-(Allylami no)-17-demethoxygeldanamycin in patients with papillary and clear cell renal cell carcinoma. Invest New Drugs 24: 543-546, 2006.
20. Heath EI, Gaskins M, Pitot HC, Pili R, Tan W, Marschke R, Liu G, Hillman D, Sarkar F, Sheng S, et al: A phase II trial of 17-allylamino-17-demethoxygeldanamycin in patients with hormone-refractory metastatic prostate cancer. Clin Prostate Cancer 4: 138-141, 2005.

21. Oh WK, Galsky MD, Stadler WM, Srinivas S, Chu F, Bubley G, Goddard J, Dunbar J and Ross RW: Multicenter phase II trial of the heat shock protein 90 inhibitor, retaspimycin hydrochloride (IPI-504), in patients with castration-resistant prostate cancer. Urology 78: 626-630, 2011.

22. Solit DB, Osman I, Polsky D, Panageas KS, Daud A, Goydos JS, Teitcher J, Wolchok JD, Germino FJ, Krown SE, et al: Phase II trial of 17-allylamino-17-demethoxygeldanamycin in patients with metastatic melanoma. Clin Cancer Res 14: 8302-8307, 2008.

23. Pacey S, Gore M, Chao D, Banerji U, Larkin J, Sarker S, Owen K, Asad Y, Raynaud F, Walton M, et al: A Phase II trial of 17-allylamino, 17-demethoxygeldanamycin (17-AAG, tanespimycin) in patients with metastatic melanoma. Invest New Drugs 30: 341-349, 2012.

24. Cercek A, Shia J, Gollub M, Chou JF, Capanu M, Raasch P, Reidy-Lagunes D, Proia DA, Vakiani E, Solit DB and Saltz LB: Ganetespib, a novel Hsp90 inhibitor in patients with KRAS mutated and wild type, refractory metastatic colorectal cancer. Clin Colorectal Cancer 13: 207-212, 2014

25. Socinski MA, Goldman J, El-Hariry I, Koczywas M, Vukovic V, Horn L, Paschold E, Salgia R, West H, Sequist LV, et al: A multicenter phase II study of ganetespibmonotherapy in patients with genotypically defined advanced non-small cell lung cancer. Clin Cancer Res 19: 3068-3077, 2013.

26. Sequist LV, Gettinger S, Senzer NN, Martins RG, Jänne PA, Lilenbaum R, Gray JE, Iafrate AJ, Katayama R, Hafeez N, et al: Activity of IPI-504, a novel heat-shock protein 90 inhibitor, in patients with molecularly defined non-small-cell lung cancer. J Clin Oncol 28: 4953-4960, 2010.

27. Dickson MA, Okuno SH, Keohan ML, Maki RG, D'Adamo DR, Akhurst TJ, Antonescu CR and Schwartz GK: Phase II study of the HSP90-inhibitor BIIB021 in gastrointestinal stromal tumors. Ann Oncol 24: 252-257, 2013

28. Chandarlapaty S, Scaltriti M, Angelini P, Ye Q, Guzman M, Hudis CA, Norton L, Solit DB, Arribas J, Baselga J and Rosen N: Inhibitors of HSP90 block p95-HER2 signaling in Trastuzumab-resistant tumors and suppress their growth. Oncogene 29: 325-334, 2010

29. Sequist LV, Waltman BA, Dias-Santagata D, Digumarthy $S$, Turke AB, Fidias P, Bergethon K, Shaw AT, Gettinger S, Cosper AK, et al: Genotypic and histological evolution of lung cancers acquiring resistance to EGFR inhibitors. Sci Trans Med 3: 75ra26, 2011

30. Tillotson B, Slocum K, Coco J, Whitebread N, Thomas B, West KA, MacDougall J, Ge J, Ali JA, Palombella VJ, et al: Hsp90 (heat shock protein 90) inhibitor occupancy is a direct determinant of client protein degradation and tumor growth arrest in vivo. J Biol Chem 285: 39835-39843, 2010.

31. Goetz MP, Toft D, Reid J, Ames M, Stensgard B, Safgren S, Adjei AA, Sloan J, Atherton P, Vasile V, et al: Phase I trial of 17-allylamino-17-demethoxygeldanamycin in patients with advanced cancer. J Clin Oncol 23: 1078-1087, 2005.

32. Banerji U, O'Donnell A, Scurr M, Pacey S, Stapleton S, Asad Y, Simmons L, Maloney A, Raynaud F, Campbell M, et al: Phase I pharmacokinetic and pharmacodynamic study of 17-allylamino, 17-demethoxygeldanamycin in patients with advanced malignancies. J Clin Oncol 23: 4152-4161, 2005.

33. Nowakowski GS, McCollum AK, Ames MM, Mandrekar SJ, Reid JM, Adjei AA, Toft DO, Safgren SL and Erlichman C: A phase I trial of twice-weekly 17-allylamino-demethoxy-geldanamycin in patients with advanced cancer. Clin Cancer Res 12: 6087-6093, 2006.

34. Pratt WB, Morishima Y, Peng HM and Osawa Y: Proposal for a role of the Hsp90/Hsp70-based chaperone machinery in making triage decisions when proteins undergo oxidative and toxic damage. Exp Biol Med (Maywood) 235: 278-289, 2010.

35. Solit DB, Basso AD, Olshen AB, Scher HI and Rosen N: Inhibition of heat shock protein 90 function down-regulates Akt kinase and sensitizes tumors to Taxol. Cancer Res 63:2139-2144, 2003. 